\title{
Public Participation in Environmental Management in Constitutional and Legal Frameworks
}

\author{
Chutarat Chompunth \\ School of Social and Environmental Development, National Institute of Development Administration, \\ 118 M.3, Serithai Road, Klong-Chan, Bangkapi, Bangkok, 10240, Thailand
}

Received 2012-11-16, Revised 2012-12-10; Accepted 2013-03-08

\begin{abstract}
In the past, environmental management in Thailand was only the responsibility of the government. Citizens had to comply with all the related laws and regulations. After participating in Stockholm Conference in 1972, Thai government recognized the need for environmental management. The Enhancement and Conservation of National Environmental Quality Act 1975 was enacted and it changed the overview of environmental management in Thailand. Public participation has been continuously adopted into Thai regulatory framework since the government recognized its importance and capability for solving environmental conflicts in Thailand. Environmental laws and regulations relating to public participation practice in Thailand were reviewed and analyzed. Secondary data from articles, journals and books were evaluated. It was found that Thai government's approach to handling the environmental problems and conflicts under the Thai laws and mechanisms was top-down management and obviously ineffective. In particular, decisions about environmental protection and management often fail to integrate the opinions of the public. Public participation practice was often avoided and limited. The decision-makers preferred to keep control over the decision and refused to share their authority. The public has few opportunities to influence the decisions. It could be said that Thai environmental laws and regulations are not effectively implemented and enforced. An ineffective implementation and enforcement of the regulations promulgating public participation was an important obstacle to achieve effective process and this could lead to more environmental problems and conflicts.
\end{abstract}

Keywords: Environmental Laws, Public Participation, Environmental Conflicts

\section{INTRODUCTION}

The dramatic changes in the fundamental structures in Thailand have been a cause of environmental and social conflicts. This problem needs an effective approach to dealing with, including legal support. In the Thai political and legal system, the government has absolute power and full authorization to manage and preserve natural resources and the environment. In the past, environmental management in Thailand was only the responsibility of the government. All policies, strategies and enforcement activities concerning environment and natural resources were thus, in the hands of the authorities. Citizens had to comply with all the related laws and regulations. The Thai government did not take critically to protect the environment and natural resources.

In 1972, after participating in the Stockholm Conference on the human environment, the government recognised the need for environmental management. Subsequently, the National Environmental Board (NEB) and the Office of the National Environment Board (ONEB) which served as its Secretariat were established as a central authority to coordinate environmental management. These were the first government organisations responsible for handling environmental problems in the country (Reutergardh and Yen, 1997). Since then the environmental management process 
subsequently started and environmental laws and regulations were initiated. The Thai legal system was influenced by the international mainstream which emphasised the right of the public to participate in environmental protection (Chess, 2000).

In 1975, Thailand's first national environmental quality act, the Enhancement and Conservation of National Environmental Quality (NEQA) Act B.E. 2518 (1975), was enacted and it radically changed the overview on environmental management in Thailand. The Prime Minister was the Chairman of the NEB with nine ministers as members. Established in 1992, the office of environmental policy and planning, the department of environmental quality promotion and the pollution control department have played important roles in the country's environmental management since then. Under this act, the issue of public participation was first identified. Decentralisation of responsibility for environmental actions to the provincial governors was implemented (Reutergardh and Yen, 1997). However, at this early stage, this legal framework was unable to effectively solve the environmental problems and public participation was not well established.

\section{MATERIALS AND METHODS}

Public participation has been continuously adopted and developed into the Thai regulatory framework since the government recognised its importance and capability for solving environmental conflicts in Thailand. Accordingly, the concept of public participation was officially introduced into Thai society through different laws and regulations, especially at national level.

\subsection{Methodology}

A qualitative research has been employed focusing on Thailand as a case study. The study drew on an initial analysis of data from the related document and research. Environmental laws and regulations relating to public participation practice in Thailand were reviewed and analysed. Secondary data from articles, journals and books were also evaluated. Content analysis of all relevant documents was conducted.

\section{RESULTS}

Thailand's core laws and regulations concerning the rights of citizens to participate in environmental management are: the Enhancement and Conservation of National Environmental Quality Act B.E. 2535 (1992);
A Prime Minister's Public Hearing Order B.E. 2539 (1996); the Constitution of the Kingdom of Thailand B.E. 2540 (1997) and The Official Information Act B.E. 2540 (1997). Most recently, in 2007, the Constitution of the Kingdom of Thailand B.E. 2550 (2007) was enacted. This new constitution explicitly responds to weaknesses of the old constitution and it is valuable to review this in order to determine its political and environmental context to correctly understand the present Thai system. These laws and regulations are examined in more detail, in particular their changes and implications in followings.

\subsection{The Enhancement and Conservation of National Environmental Quality Act B.E. 2535 (1992)}

This Act has been modified from previous versions (the 1st version B.E. 2518 (1975), the 2nd version B.E. 2521 (1978) and the 3rd version B.E. 2522 (1979)). Currently, this 4th version is still in use. The new NEQA act was introduced and came into force in June 1992. Its main purpose is to set and follow the environmental policy, plan and standards to protect the environment by providing basic provisions for environmental protection in aspects of natural resources and pollution control, as well as aiming to be a comprehensive environmental law incorporating varied aspects of environmental management in Thailand. The NEQA has also incorporated a number of initiatives, in particular a concept of public participation, aiming to implement effective environmental management and regulations. More details of these issues are provided below.

The issue of public participation is prominently highlighted in this act. Aticles 6 and 7 state that for the purpose of public participation in issues concerning the enhancement and conservation of national environment quality, people have rights to be informed and to obtain information from the government authorities. Not only is the right to be informed of environmental information provided, the NEQA assures the people rights and duties to receive compensation from the state in cases where damage is inflicted by the dispersal of pollution or any pollution resulting from the projects or activities of the government. Besides, to encourage public participation in the promotion and conservation of environmental quality, Non-Governmental Organisations (NGOs) shall be entitled to register with the Ministry of Science, Technology and Environment (MOSTE) for environmental protection and conservation of natural resources in order to comply with the law. According to this act, NGOs are encouraged in their public 
participation role of supporting better enhancement and conservation of the country's environmental quality.

Importantly, in recognition of possible pollution problems, the NEQA 1992 stipulates requirements for the Environmental Impact Assessment (EIA) procedure making the EIA process more clear and reducing the time needed for its completion (Tongcumpou and Harvey, 1994). It specifies that any projects or activities that may cause significant impacts to the environment must have an assessment of their environmental impacts before the projects or activities are implemented. This statute aims to ensure that projects or activities must be compatible with the environment.

Article 46 of the NEQA 1992 states that for the purpose of promoting environmental quality and conservation, ministers with approval from the NEB, have an authority to specify which types and sizes of projects or activities, of any government agency, state enterprise, or private party, which are likely to cause significant environmental impact, are required to submit reports on environmental assessment for submission for approval, in accordance with articles 47, 48 and 49 of this act. Evidence of the submission of these must be announced by publishing a notice in the Government Gazette. In terms of what has to be notified, procedures, rules, methods and guidelines are prescribed for the preparation of environmental impact assessment reports for each type and size of project or activity, including related documents that are required to be filed together with the report. This is because the EIA report should include a pollution mitigation plan as well as a pollution monitoring programme which have to be judged by the assessment committee prior to the project approval. In some important cases, such as a large project that may cause negative effects to the wider public, this kind of project must be approved by the cabinet.

However, there are some weak points in this statute. First, with respect to article 8 of this act, only registered NGOs are granted rights to formally participate in the decision-making process. Citizens are not able to use their rights as private individuals. Their rights must be used via non-governmental organisations. This approach does not work well because the information transmitted to the decision-makers through third parties may be distorted. Additionally, peoples' rights are not defined clearly and do not conform with the current constitution in respect of the right to know, right to access public information, right to monitor and audit the quality of environment and also the right to ask for public hearings (Tongcumpou and Harvey, 1994). Second, the general provisions related to public participation are poorly developed in the rest of this significant act (Chess, 2000; Diduck et al., 2007). Finally, the NEQA 1992 has not clearly identified how public participation is to be formally addressed in EIA procedures. As a result, the practice of implementing public participation has still to be improved.

\subsection{A Prime Minister Public Hearing Order B.C. 2539 (1996)}

This regulation was declared under the Secretariat Office of the Prime Minister as the guideline for arranging public hearing activities and is applied to any project or activity that might cause negative effects to the environment or, finally, may introduce a disagreement into a society. It includes the principles and processes in public hearings for the formal discussion of national problems or controversies. The purpose of this activity is to collect useful information from stakeholders for government decision-making so that a decision can be made on the foundation of objective facts.

Moreover, it is a significant provision prescribing the detailed procedure of how the citizen can be involved in an administrative decision-making process. Section 14 provides that citizens have the right to object to a project and to participate in the hearing to articulate their views and evidence. Since 1992, many public hearing activities have been arranged; many of them relating to huge development projects with potential effects on the quality of people's lives and the environment. In practice, however, the procedures have still been obstructed by some difficulties, for example, an unclear authority of the administrators; limitations on the projects that can have a public hearing and unsystematic procedures.

Firstly, the condition to carry out this process is not a direct duty of any department since they are not obliged by law to do so. According to article 7-9, the decision to run the hearing depends on the discretion of the minister or the provincial governor. Article 8 of this directive states that if the minister or the provincial governor considers that the project or activity will not affect the environment and will not bring great controversy to the public, the hearing will not take place. This decision is final. According to this regulation, members of public hearing committees are selected from different well-known institutions; for instance academics, members of parliament, representatives of the Council of Lawyers and some technical experts. Their main responsibilities are to monitor the process of listening to the public through these public hearing activities; to set up public hearing processes and to 
prepare public hearing reports for the Cabinet. Regarding this point, there is a view that the requirement to run the public hearing should be stipulated by law and should not depend on the judgment of the authorities (Munger, 2007).

In Thai experience, only a few public hearings were carried out and most of these hearings were carried out because of strong requests and pressure from the public. They did not take place on the initiative of the government. In addition, they were organised after the decisions about the development project or activities were already made. As a result, the public hearing in Thailand is perceived as a process that cannot stop unrest and was always too late to solve conflicts. The important cases of public hearings in Thailand, which were perceived as unsuccessful, include the Yadana gas pipeline project and, particularly, the Hin Krut power plant project.

Secondly, the applicability of this directive is limited to the state's projects only. This means that private projects are excluded, even though these projects could cause significant damage to the environment. It could be argued that development projects, either initiated by the government or private sector which may cause significant impacts to the environment, must conduct a public participation process.

Thirdly, the principles and processes for conducting public hearings are still unsystematic and complicated. There must be publicity processes concerning this activity. All basic information, such as, the appointment of committees, topics for the public hearing, summary of proposals by all related organisations, time of activity and registration period, venues for registration, how to provide information to the committees and the characteristics of people that can register to join the activity has to be officially announced and widely notified to ensure that all related persons and parties are informed. During the hearing process all relevant information, evidence and opinions from stakeholders and interested parties must be heard and be open to the public in order to avoid any influence or bias.

Because of these weak points of the directive, some have argued that the public hearing regulation should be reviewed and reenacted as a parliamentary act. These procedures have been amended and reenacted in the new regulation.

\subsection{The Official Information Act B.E. 2540 (1997)}

This Act was adopted with the principle of the recognition and guarantee of the public's right to know and to have extensive access to official information, as an indicator of public participation linked with other aspects of participation. As stated in article 9 of the act, the public's right to know is granted to any individual, whether or not they have any involvement or relationship with the cause and effect of the information they request. The people's rights to know government information ranges from the right to inspect, request a copy, get advice, make complaints and appeal and to ask the state to correct or change personal information.

According to this Act, almost all official data and information should be revealed for public perusal. Citizens have the right to access official information concerning any development project that may affect them, their communities and environment. However, some categories of information can be kept confidential where its release would jeopardize national security, international relations, or national economic or financial security. Nonetheless, if the state agency refuses to disclose some of this exempted data, the people still have the right to appeal to the Official Information Commission (OIC) to reconsider the case.

This act has overturned the traditional practice of the Thai government officials whose attitude towards government information was that it should be kept strictly confidential for official uses only. As a matter of responding to public demand to access this information, a disclosure was seen as an exception, as most data were kept in secret. However, when it was first adopted, the Act was new to the public and consequently not many people knew how to access official information and, as previously mentioned, in the Thai bureaucratic context, all official information had not been easily accessible to the public. This reflected many government officials' perceptions and is thus quite difficult to change.

\subsection{The Constitution of the Kingdom of Thailand B.E. 2540 (1997)}

This Constitution was enacted on October 11, 1997 to set out the principles of the democratic regime of government. It represents a revolution in the Thai political system (Munger, 2007). This constitution is recognised as 'the People's Constitution'. Unlike previous constitutions, its drafting processes included public participation processes and public relations activities to raise public awareness of the importance of the law. Public hearings in all 76 provinces over the country were provided in order to integrate the public's opinions and views into its drafting. 
On the issue of the environment, the 1997 Constitution has prescribed many advantages for environmental management in Thailand. It has distinctive differences from previous constitutions by providing many amendments in the environmental management area, in particular the citizen's determinations and basic rights (Munger, 2007). It promotes and supports the principle of public participation to have an important role in decision making and project development. Regarding the basic rights, the public and the local communities are allowed to be involved in all aspects of the government administration, in particular the management of natural resources and the environment. This right is identified in many clauses.

The 1997 constitution was adopted in response to broad demand for political reform and public participation in governance and for the inspection of the activities of state power (Munger, 2007). In this constitution, the government has changed the rule from the state having exclusive responsibility over environmental management to encouraging and supporting environmental management through four basic principles. These are: conservation and utilisation of natural resources and biodiversity complying with the principle of sustainable development; control and abatement of pollution that affects public health and quality of life; public participation and a provision of access to information. This constitution initially provides the basic rights of the citizens in environmental management and conservation aiming to reduce the government's sole decision-making power which is a significant highlight in the Thai constitutional record. These four principles are explained in detail below.

Firstly, the right of the public and local community to conserve and use their environment and resources sustainability is embodied in article 79 of the Constitution. This states that the government should support the people and the local community to participate in the preservation and protection of the environment and to use national resources and natural biodiversity conforming to the sustainability principle.

Secondly, the right to control and abate pollution that may affect the public health and quality of life is provided in article 56. It stipulates that the public has a right to take part in the decision-making process before the projects or activities that might cause significant effects to the environment are approved and carried out. These projects or activities need to conduct an Environment Impact Assessment (EIA) and issue a report. In particular, article 56 endorses transparency in the EIA reviewing process by stating that the independent commission must be comprised of representatives from non-governmental organisations and academics from universities to provide neutral participants that should have no bias (unlike many government officers). The EIA procedure must be followed and an independent commission must give a statement on the case.

Thirdly, regarding public participation, the constitution provides the right of the general public to be involved in all aspects of the state, in particular the management of natural resources and the environment. In this constitution, articles 46 and 56 provide the communities' and individuals' rights to manage and participate in environmental protection and to use the natural resources. The right to take part in the administrative decision procedure before the decision is taken for the projects that may cause effects on the environment is offered in article 56. The 1997 Constitution not only pays attention to the participation of individuals and local communities, but it also allows many parties to be involved, such as, local administrations, private environmental organization, or institutes of higher education. It could be said that the 1997 constitution provide the rights and equal opportunity for all members of society to manage natural resources and the environment.

Fourthly, the 1997 constitution guarantees access to information by the public. The right to gain access to information about the environment and other official information is provided in articles 58 and 59. Article 59 gives the public the right to receive information, an explanation and justifications from the State agency, State enterprise, or local government organisation, before permission is given for the operation of any projects or activities which may affect the quality of the environment, health and sanitary conditions, the quality of life, or any other material interest concerning individuals or a local community. The public also has an opportunity to express its opinions on such matters in accordance with the public hearing process as provided by law. Additionally, citizens have a right to express their point of view and have an opportunity to participate in the management, maintenance, preservation and exploitation of the environment and natural resources. The public can access information from both state and local government organisations related to the operation of projects or activities that may affect their community (Chaisomphob et al., 2004). For example, information about the construction of electricity infrastructure, which may affect the quality of the environment, health and 
sanitary conditions, the quality of life, or any other material interest concerning a local community, might be interesting and the public has a right to know about and ask for, this information.

\subsection{The Constitution of the Kingdom of Thailand B.E. 2550 (2007)}

The 2007 Constitution retains the original essences of the 1997 Constitution and introduces several new provisions which had a potential to advance the state of Thai democracy. For example, the constitution provided for transparent institutions and more checks on executive authority via the creation of several superintendent institutions. Although most of these democratising features were not effectively implemented, the new constitution also carries forward the mandate for local elections, greater decentralisation and public participation. For example, this constitution allows the citizens to place issues directly before the legislature via a petition of at least 50,000 voters. Some changes are created for more effectiveness, such as the number of voters needed for a petition is lowered to 10,000 from the 50,000 stipulated in the previous constitution.

On the issue of environmental management, the 2007 Constitution promotes and supports public participation in environmental management and conservation more than any previous constitution. Building on the 1997 Constitution, whereas the majority of the contents of these aspects in this constitution and the 1997 constitution are similar, some principles are added. It sets five fundamental principles regarding environmental management and public participation. They are: the right of the public and local community to conserve and use their environment and resources sustainability; the right to control and minimise the pollution that impacts their quality of life; the right of the individual and community to reduce the government's sole decision-making power over natural resource management; a provision of a guarantee of access to information by the public and public participation. It can be argued that the 2007 Constitution still endorses the principle of public participation, aims at producing more practical consequences and grants the public more basic rights in environmental protection, than the 1997 constitution. More details of these concerns are discussed below.

Firstly, the new Constitution of 2007 guarantees the right of a person as a member of a community, a local community or a traditional community to manage and handle natural resources and the environment as a basic right. Article 66 of this constitution provides the communities' rights based on their traditions which have the right to conserve or refurbish their customs, local knowledge, good arts and culture of their community, as well as the country and to participate in the management, maintenance, preservation and exploitation of natural resources, the environment and the biological diversity in a reasonable and sustainable approach. This article mirrors article 46 of the previous constitution. Significantly, in this version a variety of institutions, such as a community, a local community or a traditional community is provided with this right instead of only people who represent the local community having this right, as was the case in the 1997 Constitution.

Secondly, the constitution provides the rights of the public to take part in the conservation, preservation and exploitation of natural resources and biological diversities in article 67. The rights to protect and preserve the environmental quality are also available. This article also indicates that any projects or activities that are likely to affect the quality of the environment are not permitted, unless their impact on the quality of the environment has been examined and evaluated and its mitigation programme is appropriate. Opinions and comments of the independent organisations, such as academic institutions, must be obtained before that project or activity is operated. Most importantly, this article requires a public hearing to be conducted for consulting the public as well as interested persons prior to the project implementation. The public hearing, as a significant method, is required, in particular, to gain opinions from independent organisations, consisting of representatives from private organisations in the field of the environment and health and from higher education institutions which provide studies in the field of the environment, natural resources or health. This is the most advanced approach to environmental management in Thailand. However, there is still no clear and comprehensive direction on how to conduct the hearing according to the present Constitution. Obviously, in the Thai experience, a great number of previous hearings were unclear and problematic. A defined procedure or a supporting regulation for this issue is urgently required.

Additionally, communities are also provided the right to bring a lawsuit against a government agency, a local government organisation or other state authority which has inappropriately performed their duties. The contents are very similar to those in the previous constitution. However, there is a small difference in the text which has changed the right of a person to sue any state authority that does not perform their duties as stated in article 56 of the 1997 constitution, to the right of the community, instead of the individual's right, to a lawsuit 
against the government agencies for their failure to properly perform these duties.

Thirdly, the new constitution guarantees the right of the individual and community to limit the government's sole decision-making power over natural resource management. Article 58 states that people have the right to participate in the decision-making process of government officers in the performance of administrative functions which affect or may affect their rights and liberties.

Fourthly, similar to the previous constitution, the 2007 Constitution grants the citizens rights in accessing information. People in a community have the right to receive information, explanations and justifications from the government authorities before permission is given for the operation of any development project or activity that may have adverse impacts on the environment, health and sanitary conditions. The citizens also have the right to express their ideas to relevant agencies to assist further consideration of such matters. However, the methods on how to present their opinions are not indicated and specified, while article 59 of the 1997 Constitution allows the citizens to communicate these aspects though the public hearing.

\section{DISCUSSION}

It could be seen that there are a number of Thai laws and regulations relating to public participation in environmental management in Thailand. They provide different applications on the issue using different approaches and concepts.

Several sections of the 2007 constitution provide the rights of the public to be involved in the management of natural resources and the environment, in particular articles 57, 66 and 67. Highlighted in this constitution, the importance of public participation is emphasised for other areas of management apart from the field of environmental management. In a particular scheme, part 10 of the 2007 constitution sets a principle of state policies in relation to public participation. Article 87 states that the state should promote public participation: in the determination of policies and plans for economic and social development at both national and local levels; in political decision-making, the planning of economic and social development and the provision of public services; in the scrutiny of the exercise of the state powers and in supporting the function of civic groups to form networks to be able to express their opinions and propose their demands.
Regarding the promotion and preservation of environmental quality at the local level, the 2007 Constitution promotes the decentralisation process by empowering local government and facilitating public participation. Article 290 stipulates that a local government organisation is authorised and has responsibility for promoting and preserving environmental quality, as provided in relevant legislation, such as the Administrative Procedure Act of 1997. A local government organisation has powers and duties to manage, preserve and exploit the natural resources and environment in the area of its locality, as well as the area outside its authority, in the case where the livelihood of the inhabitants in its area may be affected. Most importantly, local government is authorised to participate in considering the approval of any project or activity outside the area of its own locality which may affect the quality of the environment, health or sanitary conditions of its inhabitants.

With respect to the provisions of the Thai constitutions and relevant laws, it can be seen that Thailand's legislation promotes, confers and formalizes the concept of public participation in managing and protecting the natural resource and environment issues. However, there are still many barriers to implementing these rights in practice. For example, the scope of the rights of citizens to participate in the environmental protection program and to use natural resources must be regulated in more detail by ordinary laws under articles 46 and 56 of the 1997 Constitution. This constitution was superseded in 2007, but there are still no provisions or supporting laws to fulfil these rights.

In addition, although article 6 of the NEQA 1992 and article 59 of the new Constitution state that a person has a right to gain access to information on projects that may have impacts or their individual life, in practice the government officers remain reluctant to provide this information. The provision process is sometime criticised as an ambiguous process.

Importantly, the government should promote and provide public education on political development and the democratic regime. Public participation under this provision is founded upon the consideration of its importance as an effective approach for the country's development (Munger, 2007). The government have to set up the public hearing before planning any development in social, economic, political or cultural activities as well as zoning that may have impacts on the interests of the public. However, these core sections of environmental management require detailed regulations 
in order to implement them. At present, the supporting regulation is yet to be adopted.

\section{CONCULSION}

It could be seen that many articles in the NEQA 1992 and the 2007 Constitution have provided the rights of the public and local authorities to participate in the decision-making process regarding projects that might cause serious impact to their life. However, the Thai government's approaches to deal with the environmental problems and conflicts under the Thai laws and mechanisms have evidently failed, environmental problems and conflicts have not been improved, as evidenced from the past history. The number of conflicts between the public and the government or the project owner has noticeably increased during the past few years. The main reasons for the failure of the legislation may result from the lack of effective enforcement of laws and regulations on public participation.

Thus, these Thai laws, which are seen as too lenient in the area of the rights of public participation in environmental management, should be revised and improved. The constitution, laws, rules and regulations must be reformed to be fair, transparent and support public participation. Finally, effective enforcement of laws is important. No matter how good they look on paper, if each stakeholder continues to go their own way without the appropriate checks and balances, conflicts would still occur and Thai people's happiness would deteriorate.

\section{REFERENCES}

Chaisomphob, T., J. Sanguanmanasak and K. Swangjang, 2004. Role of public participation in planning power plant project in Thailand. Thammasat Int. J. Sc. Tech., 9: 67-73.

Chess, C., 2000. Evaluating environmental public participation: Methodological questions. Environ. Plann. Manage., 43: 769-784. DOI: 10.1080/09640560020001674

Diduck, A., J. Sinclair, D. Pratap and G. Hostetler, 2007. Achieving meaningful public participation in the environmental assessment of hydro development: Case studies from Chamoli district, Uttarakhand, India. Impact Assessment Project Appraisal, 25: 219-231. DOI: $10.3152 / 146155107 X 217299$

Munger, F., 2007. Constitutional reform, legal consciousness and citizen participation in Thailand. Cornell Int. Law J., 40: 455-475.

Reutergardh, L.B. and N.T. Yen, 1997. The Thai environment: Prospering or suffering from development? Trends Anal. Chem., 16: 436-450. DOI: 10.1016/S0165-9936(97)00062-9

Tongcumpou, C. and N. Harvey, 1994. Implications of recent EIA changes in Thailand. Environ. Impact Assessment Rev., 14: 271-294. DOI: 10.1016/01959255(94)90023-X 